\title{
Specificity Screening of Potential Active Components from Moutan Cortex for Rat Mesangial Cells HBZY-1 by Cell Membrane Immobilized Chromatography
}

\author{
Junfei Gu1,2,3, Minghua Zhang1, Jiarui Yuan1,3, Bingjie Zhao ${ }^{1,3}$, Liang Feng1* ${ }^{*}$ Xiaobin Jia1, \\ Li Zhang1, Yuesheng Wang4, Luqi Huang2* \\ ${ }^{1}$ Key Laboratory of New Drug Delivery System of Chinese Materia Medica, Jiangsu Provincial Academy of \\ Chinese Medicine, Jiangsu Branch of China Academy of Chinese Medical Sciences, Nanjing, China \\ ${ }^{2}$ State Key Laboratory Breeding Base of Dao-Di Herbs, China Academy of Chinese Medical Sciences, Beijing, \\ China \\ ${ }^{3}$ College of Pharmacy, Nanjing University of Chinese Medicine, Nanjing, China \\ ${ }^{4}$ Institute of Chinese Medicine, China Academy of Chinese Medical Sciences, Beijing, China \\ Email: ${ }^{*}$ wenmoxiushi@163.com, ${ }^{*}$ huangluqi@263.net
}

Received 5 May 2015; accepted 20 June 2015; published 23 June 2015

Copyright (C) 2015 by authors and Scientific Research Publishing Inc.

This work is licensed under the Creative Commons Attribution International License (CC BY). http://creativecommons.org/licenses/by/4.0/

(c) $\underset{\mathrm{EY}}{\mathrm{i}}$ Open Access

\begin{abstract}
Moutan Cortex (MC) has been demonstrated to have an inhibitive effect on inflammation and oxidative stress responses in mesangial cells in our previous study. However, little is known about the components of MC contributing to this benefit. In the present study, cell membrane immobilized chromatography (CMC), a fast and useful method, was presented for screening potential active components of MC. HBZY-1 cells were incubated with MC $(200 \mu \mathrm{g} / \mathrm{mL})$ at the optimal incubation time $(90 \mathrm{~min})$. HPLC-DAD analysis and LC/ESI/MS/MS were performed to distinguish the active components and identify its structural ion fragments. The results showed that eight components binding to HBZY-1 cells were mudanoside B, paeoniflorin sulfonate, paeoniflorin, tetragalloyl glucose (isomeride), hexagalloyl glucose, mudanopiside $A$, and paeonol. In conclusion, our established CMC might be a useful method for screening potential active components in complicated traditional Chinese medicines. These components might be associated with the efficacy of MC on prevention and treatment of diabetic nephropathy.
\end{abstract}

\section{Keywords}

Cell Membrane Immobilized Chromatography, Moutan Cortex, HBZY-1 Cell, Screening

${ }^{*}$ Corresponding authors.

How to cite this paper: Gu, J.F., et al. (2015) Specificity Screening of Potential Active Components from Moutan Cortex for Rat Mesangial Cells HBZY-1 by Cell Membrane Immobilized Chromatography. Chinese Medicine, 6, 147-157.

http://dx.doi.org/10.4236/cm.2015.62016 


\section{Components, Diabetic Nephropathy}

\section{Background}

Diabetic nephropathy (DN), one of microvascular complications in diabetic patients as the end-stage renal disease, is the leading cause of high morbidity and mortality of diabetes mellitus (DM) throughout the word [1]. The optimal treatment for $\mathrm{DN}$ continues to evolve as newer therapies for decreasing $\mathrm{DN}$ progression through a multifaceted target [2]. Recent studies show that the beneficial effects of traditional Chinese medicines (TCMs) on the treatment and prevention of DN have attracted the increasing interest of researchers [3].

As a well-known traditional herbal medicine, Moutan Cortex (MC), the root bark of Paeonia suffruticosa Andr., has been used for DN treatment for a long time in China and other Asian countries [4]. It is worth noting that $\mathrm{MC}$ has an inhibitive effect on inflammation and oxidative stress responses in DN [5] [6]. Phytochemical study has shown that MC contains lots of chemical compounds such as paeoniflorin, oxypaeoniflorin, benzoyloxypaeoniflorin, apiopaeonoside, benzoylpaeoniflorin, paeonol, sugars, etc. [7]. Actually, as we know, not all of components in TCMs are responsible for the disease treatment [8]. Of all the components in MC, paeonol has been investigated to have the anti-diabetic effect [9]-[11]. In addition, paeoniflorin, oxypaeoniflorin, benzoyloxypaeoniflorin and paeonol could inhibit the aggregation of platelet which might exacerbate the response of DN [12]. It has also been investigated that paeoniflorin and oxypaeoniflorin have the antioxidant and anti-inflammation activities on AGEs-induced mesangial cell damage in our present study [13]. However, little is known about the mutil-components of MC contributing to the prevention and treatment of DN.

Recently, more and more methods have been developed for the screening of active components in TCMs, such as high throughput screening, and DNA sequencing [14]-[16]. Pharmacology researches have demonstrated that the action of drugs may be derived from the interaction of bioactive component molecules with some receptors or channels on cell membrane. Cell membrane immobilized chromatography (CMC), one of cell membrane affinity chromatography, is composed of the biologic membrane immobilized part and the chromatographic analysis part. Specifically, the cell membrane of organism is used as a solid phase for targeting effective components in TCMs. Then, the potential active components can be analyzed by chromatographic techniques timely. The effective components in TCMs can be screened quickly and efficiently [17]. Hence, the use of CMC by biomembrane of organism extraction together with chromatography analysis may be a powerful tool for screening potential active components in TCMs.

Therefore, the present study was conducted to establish an appropriate CMC method for screening the potential active components in MC which interacted with mesangial cells. Furthermore, these active components, which were related to the protective effect of $\mathrm{MC}$ on $\mathrm{DN}$, were revealed for the first time in our study.

\section{Materials and Methods}

\subsection{Materials and Reagents}

MC, the dried roots of Paeonia suffruticosa Andr. (Batch No. 20120415), was from Anhui Huqiao Chinese Medicine Technology Co., Ltd. (Tongling, Anhui Province). The pharmaceutical botany of the medicinal material was identified by Prof. Dekang Wu from Nanjing University of Chinese Medicine. Standard substances of paeoniflorin and paeonol, each content was more than $98 \%$ were offered by National Instisutes for Food and Drug Control. Mudanoside B, tetragalloyl glucose, hexagalloyl glucose, mudanopiside A, which the content were exceeded 98\%, were supplied by BOC Sciences (NY, USA). D-glucose was purchased from Sigma (St. Louis, MO, USA). Basal DMEM medium and fetal bovine serum (FBS) was provided by Gibco (BRL, USA). All other reagents used in this study were from commercial sources.

\subsection{Sample Preparation}

Crude slices (50 g) of MC were weighted and extracted in $250 \mathrm{~mL} 80 \%$ (v/v) ethanol for $2 \mathrm{~h}$ in a reflux system (two times). The two extracts were merged and filtered through $0.45 \mu \mathrm{m}$ membrane filter (PALL, USA). The solvent was removed in a rotary evaporator at $55^{\circ} \mathrm{C}$. The concentrated extract was then diluted to $0.5 \mathrm{~g} / \mathrm{mL}$ and 
stored at $4^{\circ} \mathrm{C}$ for further use. The chromatograms of MC extract were analyzed by HPLC-DAD at $254 \mathrm{~nm}$ (Figure 1).

\subsection{Preparation of AGEs}

Advanced glycation end products (AGEs) were prepared according to previous method [18] [19]. In brief, $5 \mathrm{~g}$ bovine serum albumin (BSA) and $9 \mathrm{~g}$ D-glucose were dissolved adequately in $100 \mathrm{~mL}$ phosphate buffer saline (PBS, $0.2 \mathrm{M}, \mathrm{pH}=7.4$ ). After being passed through $0.22 \mu \mathrm{m}$ microporous membrane filter, the solution was then incubated in $5 \% \mathrm{CO}_{2} / 95 \%$ air at $37^{\circ} \mathrm{C}$ under sterile conditions. The reaction mixture was dialyzed in $0.2 \mathrm{M}$ PBS overnight to remove unincorporated glucose molecules after the incubation of 3 months. The content of AGEs was measured by human AGEs ELISA kit, the final concentration was $858 \mathrm{mg} / \mathrm{mL}$, and then stored at $4^{\circ} \mathrm{C}$ until use.

\subsection{Cell Culture}

Rat mesangial cells line HBZY-1 was obtained from American Type Culture Collection (ATCC; Manassas, VA, USA) and cells were maintained in low-glucose Dulbecco's modified Eagle's medium (DMEM) supplemented with $10 \%$ fetal bovine serum and 80 units $/ \mathrm{mL}$ of penicillin/streptomycin. Cells were incubated in $25 \mathrm{~cm}^{2}$ plastic cell culture dishes in $5 \% \mathrm{CO}_{2} / 95 \% \mathrm{O}_{2}$ at $37^{\circ} \mathrm{C}$. All medium was renewed every 2 days to provide sufficient nutrition. After $80 \%-90 \%$ confluent layer, cells were used for the further experiments.

\subsection{Cell Membrane Extraction of Sample}

HBZY-1 cells were incubated in a plastic dish at a generating of $80 \%-90 \%$ confluent layer. AGEs of $1 \mathrm{~mL}$ was added into $9 \mathrm{~mL}$ PBS $(\mathrm{pH}=7.4)$ to induce mesangial cell dysfunction. The MC extraction $(50,100,200 \mu \mathrm{g} / \mathrm{mL})$ was then incubated with live cells at $37^{\circ} \mathrm{C}$ according to the previous description [7]. These cells were washed with $2 \mathrm{~mL}$ PBS to remove the unbound components for six times. The sixth washing eluate was retained for HPLC or LC/ESI/MS/MS analysis. Sequentially, $5 \mathrm{~mL}$ dissociation solution containing citric acid (pH 4.0) was added to dissociate the binding molecules at $37^{\circ} \mathrm{C}$ for $60 \mathrm{~min}$. The liquid supernatants of $5 \mathrm{~mL}$ were evaporated to dryness by high-purity nitrogen for $12 \mathrm{~h}$ at room temperature. Chromatographic methanol of $0.8 \mathrm{~mL}$ was added to each of them to dissolve the samples dryness. After vortex-mixing for $2 \mathrm{~min}$, the supernatants of all the samples were taken and evaporated to dryness again for $5 \mathrm{~h}$ at room temperature. The residue was redissolved in $0.2 \mathrm{~mL}$ methanol followed by vortex-mixing for $2 \mathrm{~min}$ and centrifugation at 11,000 $\mathrm{g}$ for $10 \mathrm{~min}$. Finally, the supernatants of all the samples were taken for HPLC and LC/ESI/MS/MS analysis.

\subsection{HPLC Analysis}

HPLC analysis system of Agilent 1200 series (Agilent Technologies, Santa Clara, CA, USA) equipped with a diode array detector (DAD), a quaternary pump, a column heater-cooler and an autosampler was performed to separate and analyze these components of MC and eluates. The samples were separated on an Agilent TC- $\mathrm{C}_{18}$ column $(4.6 \mathrm{~mm} \times 250 \mathrm{~mm}, 5 \mu \mathrm{m})$. The mobile phase gradient conditions consisted of acetonitrile (A) and $0.1 \%$ formic acid (B) was $0-20 \mathrm{~min}, 5 \%-10 \% \mathrm{~A} ; 20-30 \mathrm{~min}, 10 \% \mathrm{~A} ; 30-80 \mathrm{~min}, 10 \%-18 \% \mathrm{~A} ; 80-120 \mathrm{~min}$, $18 \%-50 \% \mathrm{~A}$. The flow rate was $0.8 \mathrm{~mL} / \mathrm{min}$ and the column temperature was maintained at $25^{\circ} \mathrm{C}$ with a $10 \mu \mathrm{L}$

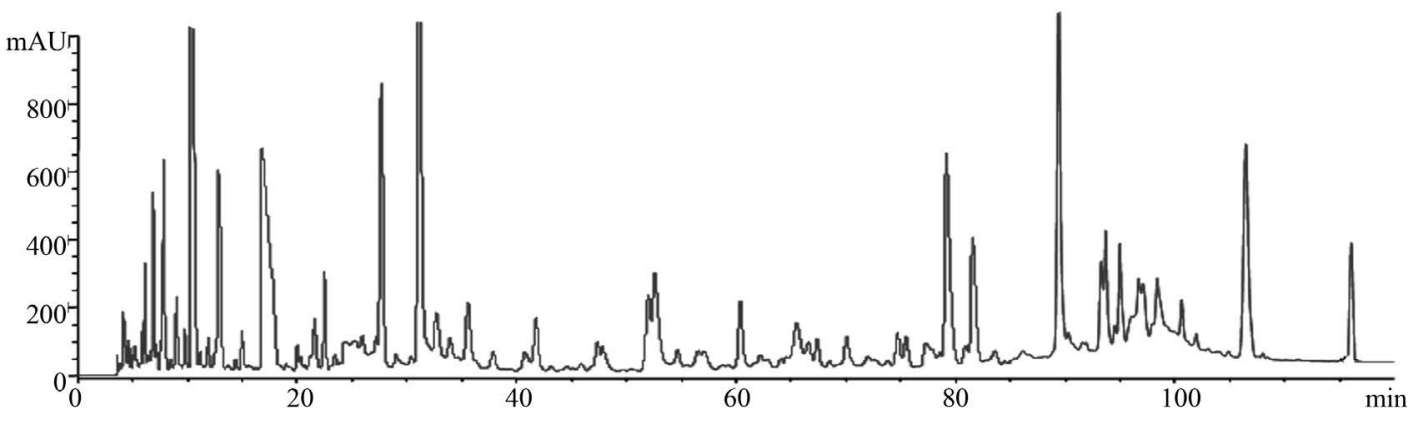

Figure 1. HPLC-DAD chromatograms was detected at $254 \mathrm{~nm}$ of MC extracted in $80 \%(\mathrm{v} / \mathrm{v})$ ethanol. 
injection volume at $254 \mathrm{~nm}$.

\subsection{LC/ESI/MS/MS Analysis for Identification of Compounds}

In this study, LC/ESI/MS/MS analysis was used to identify the compounds which were dissociated from cell membrane of HBZY-1 cells. The analysis was performed under negative-ion mode by ThermoQuest mass spectrometer (San Jose, CA, USA). The optimal operating parameters were as follows: ion spray voltage, $-4 \mathrm{kV}$; the nebulizer gas $\left(\mathrm{N}_{2}\right): 0.45 \mathrm{~L} / \mathrm{min}$; curtain gas $\left(\mathrm{N}_{2}\right): 0.2 \mathrm{~L} / \mathrm{min}$; declustering potential 1 (DP1): $-20 \mathrm{~V}$; focusing potential (FP): $-80 \mathrm{~V}$; declustering potential 2 (DP2): $-20 \mathrm{~V}$. The mass spectrometer was detected over a range of $\mathrm{m} / \mathrm{z} 80$ to 1000 in the full scan mode.

\subsection{Statistical Analysis}

All data were expressed as means \pm standard deviation (SD). Statistical analysis was performed by GraphPad Prism TM 5.0 statistical package with analysis of variance. Comparison between groups was using t-test. The value of $p$ less than 0.05 was considered to be a statistically significant difference.

\section{Results and Discussion}

\subsection{The Optimization of Conditions in Cell Membrane Immobilization}

The incubation concentration and incubation time are two important factors for CMC. Taken cells viability into consideration, different concentration extracts of $\mathrm{MC}$ including $50,100,200 \mu \mathrm{g} / \mathrm{mL}$ were examined to screen the optimal incubation concentration. As shown in Figure 2(A) and Figure 2(B), after being incubated with three concentrations of MC, the most components of MC had a high peak area at the concentration of $200 \mu \mathrm{g} / \mathrm{mL}$. It indicated that $\mathrm{MC}$ of $200 \mu \mathrm{g} / \mathrm{mL}$ had a better interaction with HBZY-1 cells. To make sure a better incubation for screening of components, $200 \mu \mathrm{g} / \mathrm{mL}$ MC was introduced for the cell membrane immobilization in our experiments. In addition, the selected concentration is consistent with that used in the evaluation of efficacy in our previous study [20].

Another important factor in CMC is the incubation time for the binding of components of MC to HBZY-1 cells. Different incubation time might affect the binding level of molecules to targets on cell membrane. Generally, the incubation time was $30 \mathrm{~min}$ as described by previous study in platelets or macrophages [17] [21]. In our present study, different time points including 15, 30, 60, 90, 120 min were examined for the most appropriate incubation time in HBZY-1 cells immobilized system. As shown in Figure 3(A) and Figure 3(B), only 6 peaks were found in $15 \mathrm{~min}$, whereas, 8 peaks were shown after $30 \mathrm{~min}$. The peak areas of these 8 peaks were increased from $30 \mathrm{~min}$ to $90 \mathrm{~min}$ in a time-dependent manner. However, there were no more peaks and significant increase of peak area of 8 peaks in the chromatogram at $120 \mathrm{~min}$. These data suggested that $90 \mathrm{~min}$ was the optimal time for the incubation.

Eventually, HBZY-1 cells were incubated with MC at the concentration of $200 \mu \mathrm{g} / \mathrm{mL}$ for $90 \mathrm{~min}$. The optimal incubation time and concentration were used for the immobilization.

\subsection{Cell Membrane Immobilization of Components in MC}

Studies show that cell membrane immobilized chromatography (CMC) is a powerful tool for screening of active compounds in TCM extract relying on the living cells incubated in the culture flask associated with the pathogenesis through the relevant passageway. Hence, there are two important factors in potential active components screening from $\mathrm{MC}$ in the biologic membrane immobilized part: the style of cell membrane and the pathogenic passageway participating in $\mathrm{DN}$.

It is well known that the targets related to pathological changes on the cell membrane are not identical in different types of cells. There is specific for the binding of bioactive components by the immobilization of different cell membranes. Reports have shown that mesangial cells, one of the main cell types of glomerulus, play important roles in the development of chronic kidney diseases including DN [22]. Hence, HBZY-1 cells were used for immobilizing potential active components of MC.

AGEs, derived from the non-enzymatic glycation reaction, have been found to accumulate in glomerular basement membrane and mesangial cells and are demonstrated to involve in the progression of DN [23]. The in- 


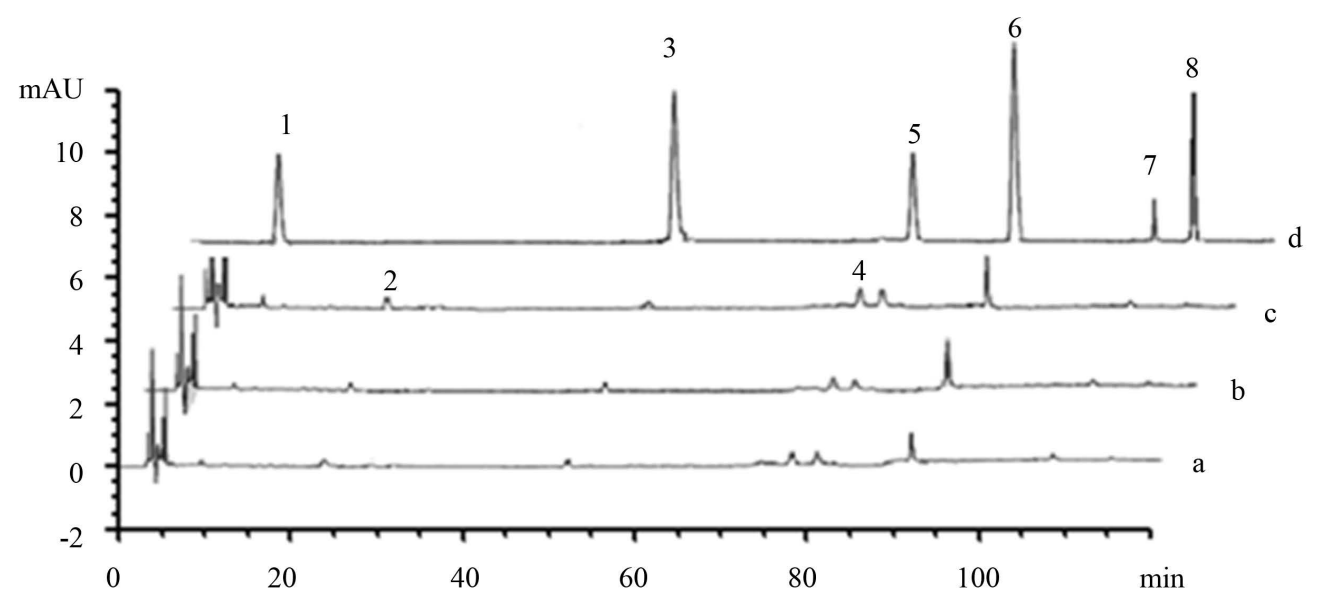

(A)

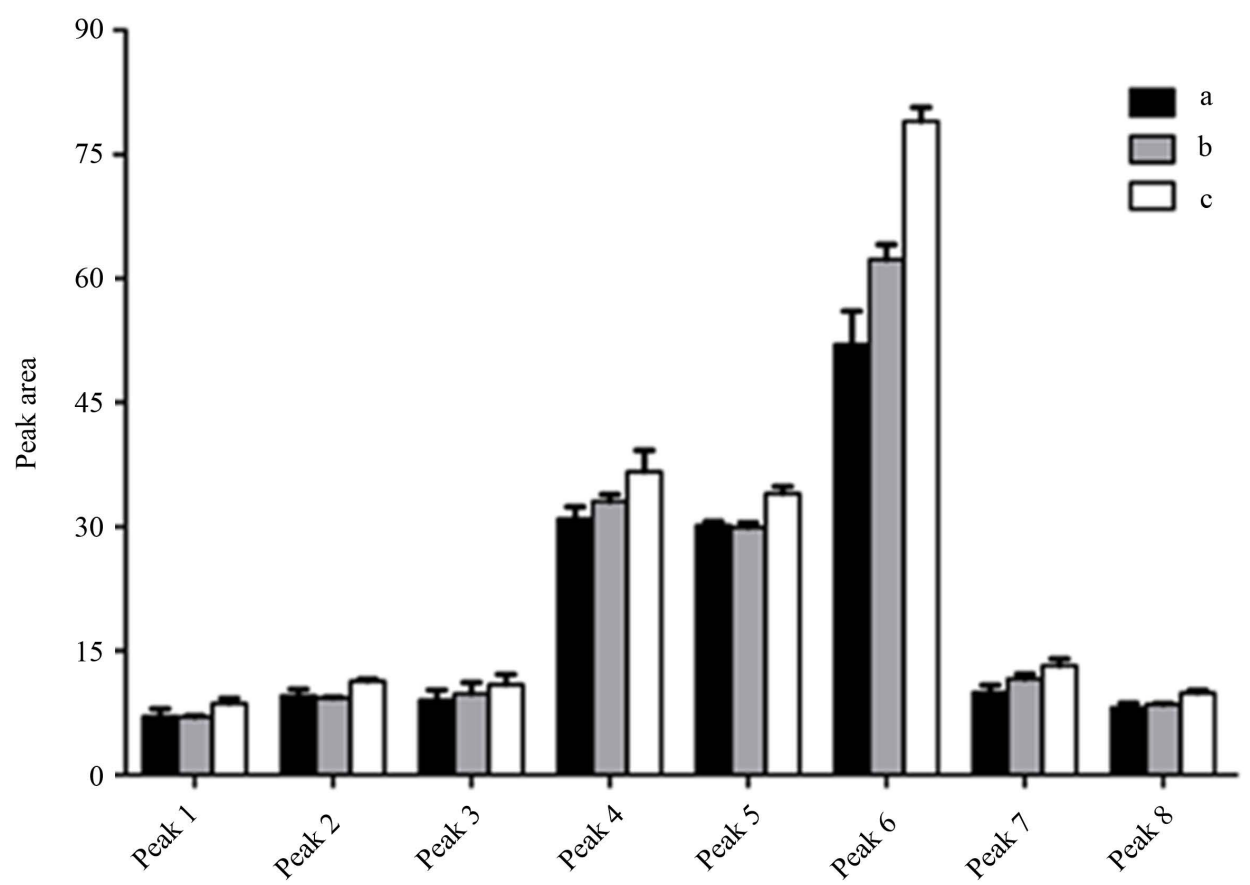

(B)

Figure 2. HPLC-DAD chromatograms was detected at $254 \mathrm{~nm}$ of $\mathrm{MC}$ after incubation with HBZY-1 cells in different concentrations (A). The peak area of 8 components of MC in different concentrations (B). (a) MC of 50, (b) MC of 100, (c) MC of $200 \mu \mathrm{g} / \mathrm{mL}$ at $37^{\circ} \mathrm{C}$, (d) the mixed standard of (1) mudanoside B; (3) paeoniflorin; (5) tetragalloyl glucose; (6) hexagalloyl glucose; (7) mudanopiside A; (8) paeonol.

teraction between AGEs and their specific receptors RAGE (AGEs-RAGE) on HBZY-1 cells membrane could stimulate the over-expressions of receptors and trigger signaling events contributing to the cells damage [24]. More importantly, the active components of MC play a protective role in the pathogenesis of mesangial cells under pathological conditions. Consequently, in the present study, AGEs were introduced to induce mesangial cells dysfunction for immobilizing these potential active components of MC which were binding to cell membrane.

After the analysis of HPLC in samples of the incubation buffer of MC, the sixth eluate and blank dissociation eluate, the result of immobilization product was shown in Figure 4. We could easily find that there were 8 peaks of $\mathrm{MC}$ in immobilized sample after being compared with $\mathrm{MC}$ extract, the sixth eluate and blank dissociation 


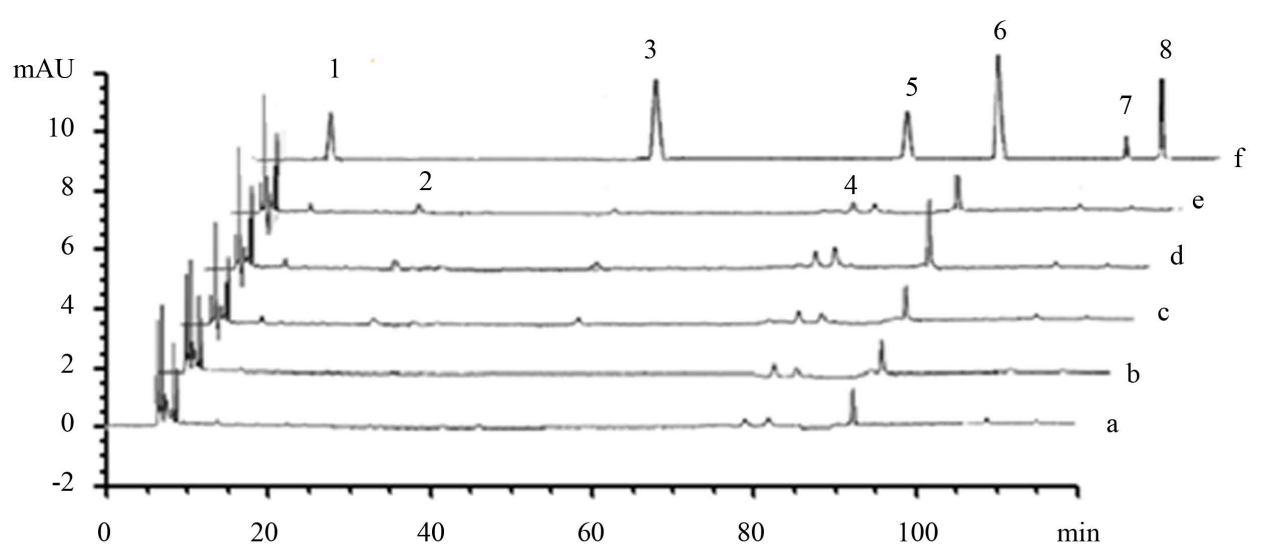

(A)

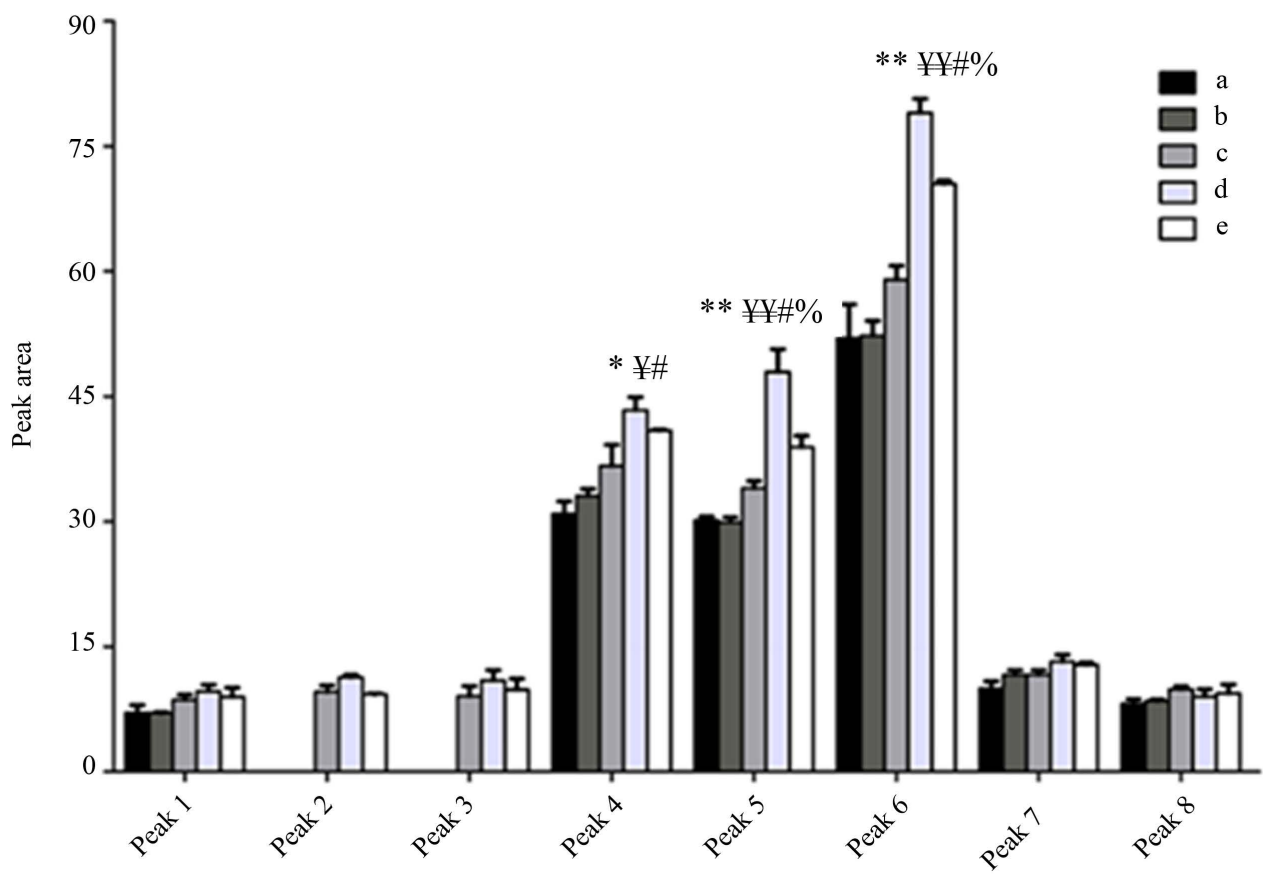

(B)

Figure 3. HPLC-DAD chromatograms detected at $254 \mathrm{~nm}$ of MC after incubation with HBZY-1 cells (A) and the peak area of 8 components of MC (B) at (a) $15 \mathrm{~min}$, (b) $30 \mathrm{~min}$, (c) $60 \mathrm{~min}$, (d) $90 \mathrm{~min}$, (e) $120 \mathrm{~min}$, (f) the mixed standard of (1) mudanoside B; (3) paeoniflorin; (5) tetragalloyl glucose; (6) hexagalloyl glucose; (7) mudanopiside A; (8) paeonol. * $\mathrm{p}<0.05$, (d) vs. (a); ${ }^{* *} \mathrm{p}<0.01$, (d) vs. (a); ${ }^{*} \mathrm{p}<0.05$, (d) vs. (b); ${ }^{¥ ¥} \mathrm{p}<0.01$, (d) vs. (b) $;{ }^{\#} \mathrm{p}<0.05$, (d) vs. (c); $\% \mathrm{p}<0.05$, (d) vs. (e).

eluate. The results indicated that peaks d1-d8 were the major components binding to cell membrane of HBZY-1. They might be the potential active components of MC for HBZY-1mesangial cells dysfunction.

\subsection{Identification of Detected Components}

As a powerful technique for identification of molecular, LC/ESI/MS/MS was introduced for the identification of components in the present study. The components in immobilized sample could be directly identified using LC/ESI/MS/MS analysis. The MS spectra of $\mathrm{d} 1-\mathrm{d} 8$ were shown in Figure 5 and the information was listed in Table 1. These components were identified as mudanoside B, paeoniflorin sulfonate, paeoniflorin, tetragalloyl glucose (isomeride), hexagalloyl glucose, mudanopiside A, paeonol according to the MS ion fragments (Figure 6).

By comparing the MS spectra, retention time and UV spectra with published literature data and standard sub- 
Table 1. Characterization of 8 components in MC after incubation with HBZY-1 cells by LC/ESI/MS/MS.

\begin{tabular}{ccccc}
\hline No. & $\mathrm{t}_{\mathrm{R}} / \mathrm{min}$ & {$[\mathrm{M}-\mathrm{H}]^{-}$} & $(-) \mathrm{ESI}_{-M S^{2}} \mathrm{~m} / \mathrm{z}(\%$ base peak $)$ & Compounds \\
\hline 1 & 11.0 & 463 & $443,331,169$ & mudanoside B \\
2 & 23.66 & 543 & - & paeoniflorin sulfonate \\
3 & 52.44 & 479 & $449,327,165,121$ & paeoniflorin \\
4 & 68.74 & 787 & $635,617,447,277,169,125$ & tetragalloyl glucose \\
5 & 72.05 & 787 & $635,617,447,277,169,125$ & tetragalloyl glucose \\
6 & 89.61 & 1091 & $939,769,169$ & hexagalloyl glucose \\
7 & 107.65 & 613 & $461,431,165,151,121$ & mudanopiside A \\
8 & 113.73 & 165 & 150,122 & paeonol \\
\hline
\end{tabular}

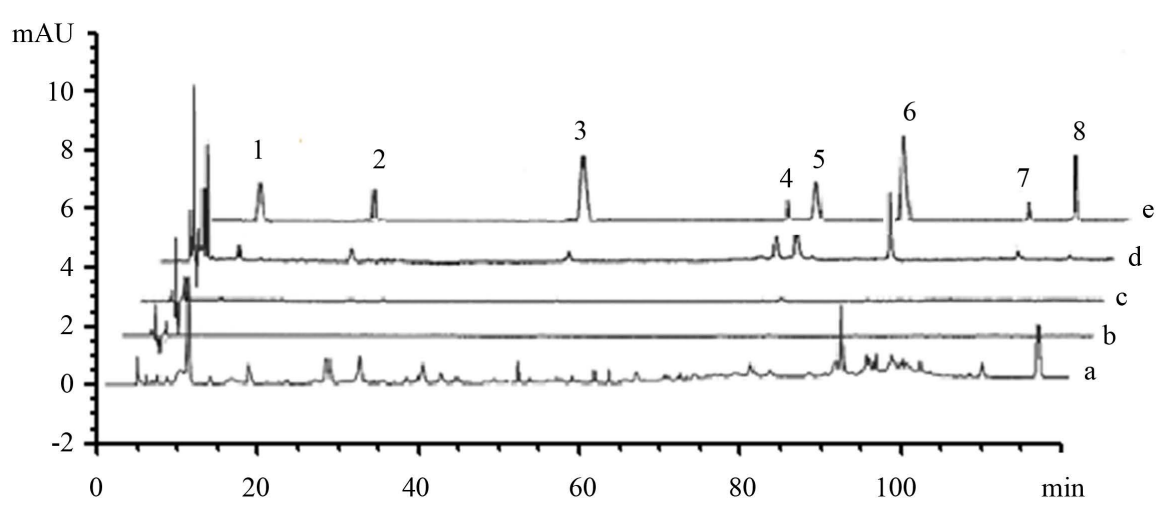

Figure 4. Chromatogram of the incubation of MC detected by HPLC-DAD (a), final washing eluate of biomembrane interacted with PBS (b), blank desorption eluate of biomembrane (c), desorption eluate of biomembrane interacted with $\mathrm{MC}$ (d), the mixed standard of (1) mudanoside B; (3) paeoniflorin; (5) tetragalloyl glucose; (6) hexagalloyl glucose; (7) mudanopiside A; (8) paeonol (e). Sample was detected at $254 \mathrm{~nm}$.

stances [25], the components for peak $\mathrm{d} 3$ and $\mathrm{d} 8$ were identified as paeoniflorin and paeonol. Peak d1 exhibited an $[\mathrm{M}-\mathrm{H}]$-ion at $\mathrm{m} / \mathrm{z} 463$ was tentatively identified as mudanoside $\mathrm{B}$ in that their ion fragments at $\mathrm{m} / \mathrm{z} 331$ (a loss of a pentose (132 Da)) and m/z 169 (losses of a pentose (132 Da) according to previous references [25] [26].

It was well known that there was no components showing the [M-H]-ion at $\mathrm{m} / \mathrm{z} 543$ in $\mathrm{MC}$, but $\mathrm{d} 2$ was identified as paeoniflorin sulfonate by comparison with the literature data previously [27]. Hence, it might be the product of the processing drug of MC which was changed from paeoniflorin.

It could also be easily seen that peak $\mathrm{d} 4$ and $\mathrm{d} 5$ had similar behavior displaying $[\mathrm{M}-\mathrm{H}]$-ions at $\mathrm{m} / \mathrm{z} 787$ in the ESI mass spectra, so it is very possible that they were isomeride. Their MS/MS spectra showed ion fragments at $\mathrm{m} / \mathrm{z} 635,617,447,277169$ and 125 with the losses of three gallic acids and a galloyl radical. Thus, they were proposed to be tetragalloyl glucose.

Peak d6 was identified as hexagalloyl glucose due to its $[\mathrm{M}-\mathrm{H}]$-ions at $\mathrm{m} / \mathrm{z} 1091$ in the full mass spectra. The greater 304 molecular weight of d6 compound than d4 and d5 was consistent with additional substitution of a galloyl group. The ion fragments of $\mathrm{d} 6$ at $\mathrm{m} / \mathrm{z} 939$ in that the losses of a gallic acid. For peak $\mathrm{d} 8$, it exhibited a [M-H]-ion at $\mathrm{m} / \mathrm{z}$ 613. Its ion fragments at 151 and 121 attributed to [methoxybenzoic acid-H] and [benzoic acid-H]. The ion fragment at m/z 165 was reasonably identified as the pinane skeleton. Hence, compound d8 was assigned to be mudanpioside $\mathrm{A}$.

MC is a well-known traditional herbal medicine that has been shown to hold a protective effect on DN. In the present study, the pharmacological activities of paeoniflorin and paeonol have been detected in anti-inflammation and anti-oxidation effect [13] [27] [28]. The pharmacological effect of other components will be investigated in our future study. 
(d1)
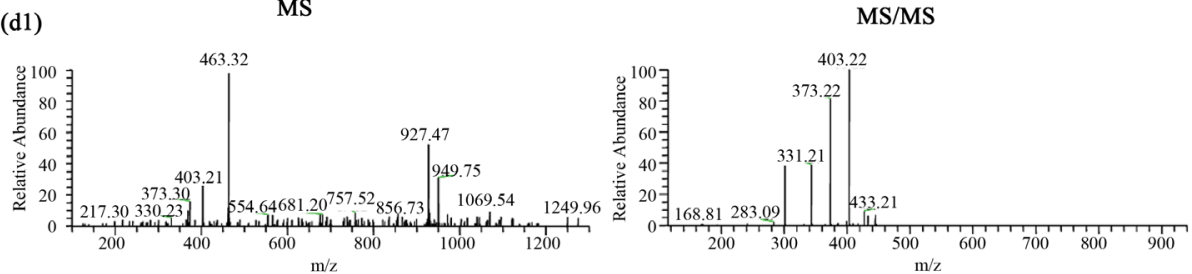

(d2)
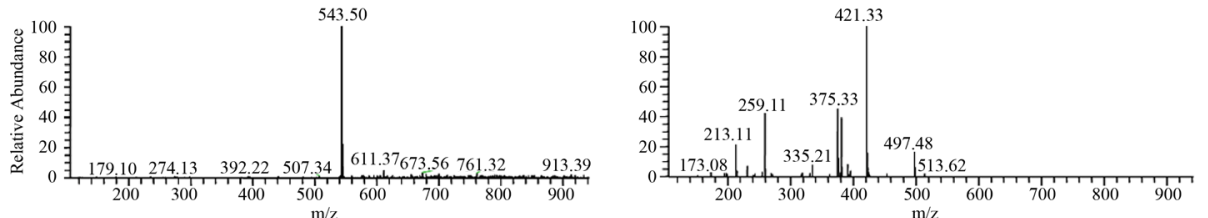

(d3)
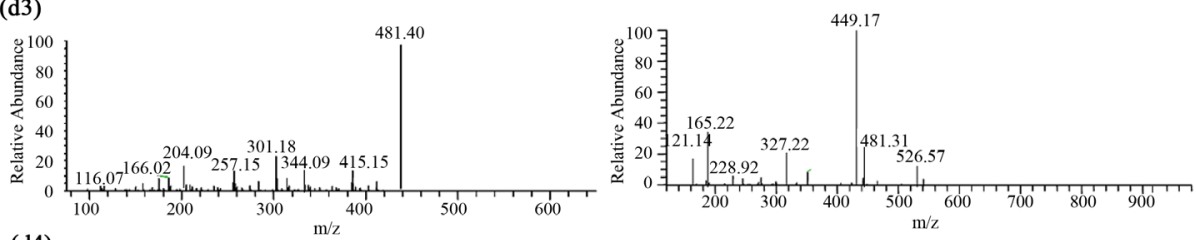

(d4)
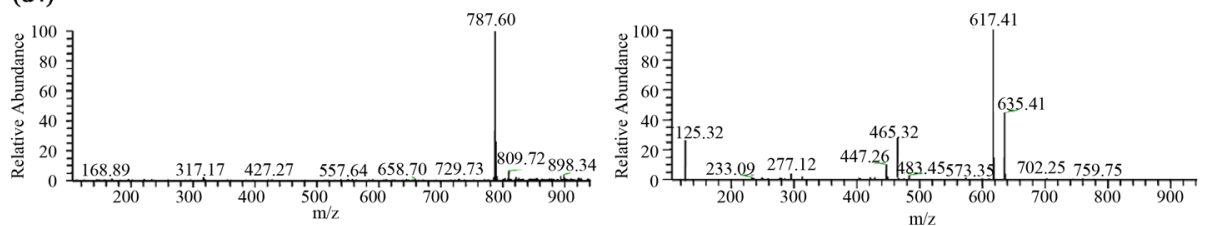

(d5)
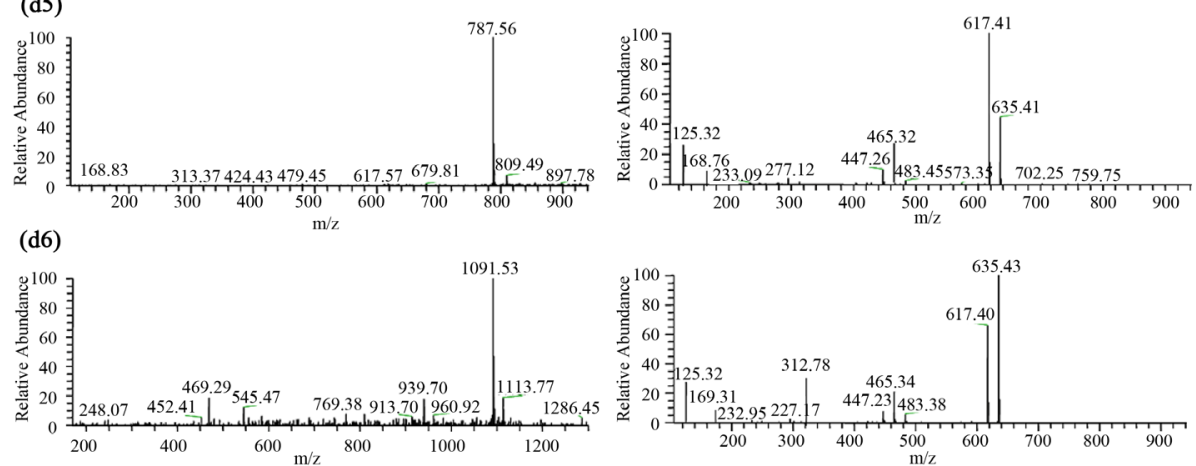

(d7)
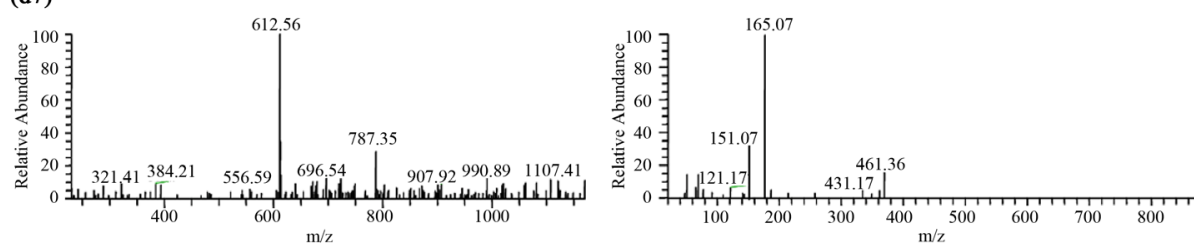

(d8)

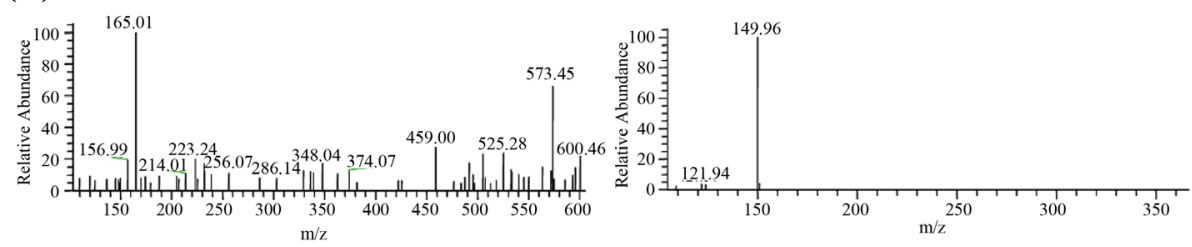

Figure 5. MS spectra of d1-d8 screened by cell membrane immobilized chromatography. (d1) mudanoside B; (d2) paeoniflorin sulfonate; (d3) paeoniflorin; (d4) tetragalloyl glucose; (d5) tetragalloyl glucose; (d6) hexagalloyl glucose; (d7) mudanopiside A; (d8) paeonol. 


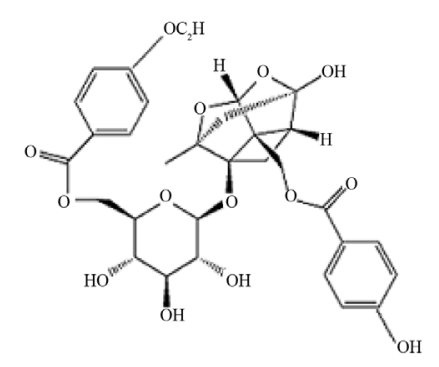

(d1) mudanoside B<smiles>O=C(COC1OC(OC(=O)c2cc(O)c(O)c(O)c2)C(OC(=O)c2cc(O)c(O)c(O)c2)C(O)C1OC(=O)c1cc(O)c(O)c(O)c1)c1cc(O)c(O)c(O)c1</smiles>

(d4) tetragalloyl glucose

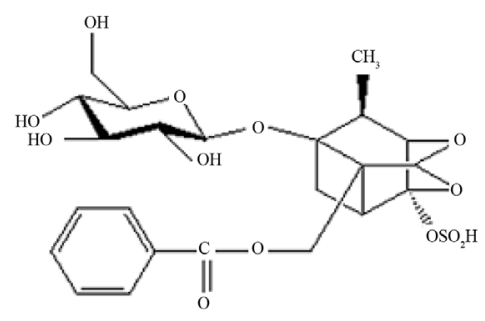

(d2) paeoniflorin sulfonate<smiles>O=C(OC1C(C(=O)c2cc(O)c(O)c(O)c2)OC(OCC(=O)C(O)C2C=C(O)C(O)C(O)C2)C(O)C1O)c1cc(O)c(O)c(O)c1</smiles>

(d5) tetragalloyl glucose

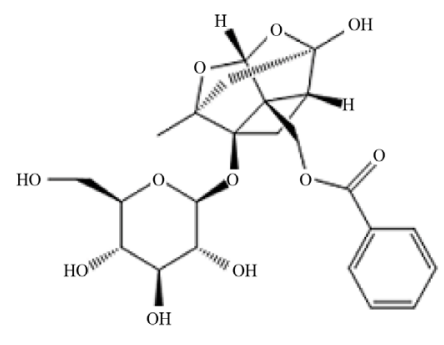

(d3) paeoniflorin<smiles>O=C(OC1C(OC(=O)c2cc(O)c(O)c(O)c2)C(OC(=O)c2cc(O)c(O)c(O)c2)C(OC(=O)c2cc(O)c(O)c(O)c2)C(OC(=O)c2cc(O)c(O)c(O)c2)C1OC(=O)c1cc(O)c(O)c(O)c1)c1cc(O)c(O)c(O)c1</smiles>

(d6) hexagalloyl glucose

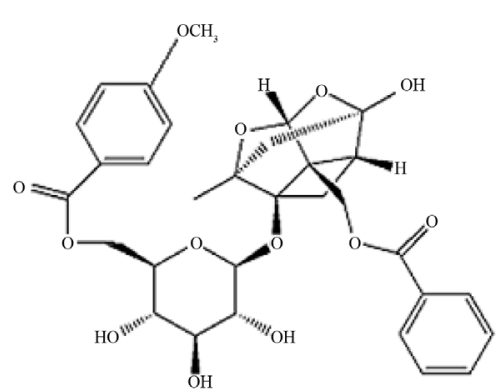

(d7) mudanpioside A

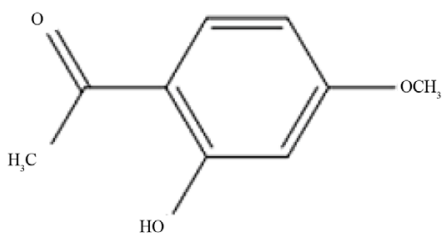

(d8) paeonol

Figure 6. The structures of d1-d8 screened by cell membrane immobilized chromatography.

\section{Conclusion}

In the present study, CMC which relied on the living HBZY-1 cells incubated in the culture flask associated with the DN pathogenesis through the relevant passageway by biologic membrane immobilization part and LC/ ESI/MS/MS part was presented for screening potential active components of MC. Finally, eight potential active components were obtained in MC binding to HBZY-1 cells. In conclusion, CMC might be a beneficial method in searching potential active components in complicated TCMs.

\section{Acknowledgements}

The authors gratefully acknowledge the financial support of the National Natural Science of China (81202906), Natural Science Foundation of Jiangsu (BK2012491), Major changes in the central level support projects (2060302) and National Natural Science Foundation of China (81130070).

\section{Conflict of Interests}

We declare that there is no conflict of interest. No author has any financial interest or conflict of interest involved with this study. 


\section{Authors' Contributions}

JFG, MHZ, JRY, BJZ, LZ, XBJ and YSW contributed to the study design, analysis, and interpretation of data. LF and LQH participated in statistical analysis and drafted the manuscript. All authors approved the final manuscript.

\section{References}

[1] Fox, C.S., Larson, M.G., Leip, E.P., Meigs, J.B., Wilson, P.W. and Levy, D. (2005) Glycemic Status and Development of Kidney Disease: The Framingham Heart Study. Diabetes Care, 28, 2436-2440. http://dx.doi.org/10.2337/diacare.28.10.2436

[2] Choudhury, D., Tuncel, M. and Levi, M. (2010) Diabetic Nephropathy-A Multifaceted Target of New Therapies. Discovery Medicine, 10, 406-415.

[3] Poon, T.Y., Ong, K.L. and Cheung, B.M. (2011) Review of the Effects of the Traditional Chinese Medicine Rehmannia Six Formula on Diabetes Mellitus and Its Complications. Journal of Diabetes, 3, 184-200. http://dx.doi.org/10.1111/j.1753-0407.2011.00130.x

[4] Ha, D.T., Tuan, D.T., Thu, N.B., Nhiem, N.X., Ngoc, T.M., Yim, N. and Bae, K. (2009) Palbinone and Triterpenes from Moutan Cortex (Paeonia suffruticosa, Paeoniaceae) Stimulate Glucose Uptake and Glycogen Synthesis via Activation of AMPK in Insulin-Resistant Human HepG2 Cells. Bioorganic \& Medicinal Chemistry Letters, 19, 5556-5559. http://dx.doi.org/10.1016/j.bmcl.2009.08.048

[5] Wu, M. and Gu, Z. (2009) Screening of Bioactive Compounds from Moutan Cortex and Their Anti-Inflammatory Activities in Rat Synoviocytes. Evidence-Based Complementary and Alternative Medicine, 6, 57-63. http://dx.doi.org/10.1093/ecam/nem066

[6] Rho, S., Chung, H.S., Kang, M., Lee, E., Cho, C., Kim, H., Park, S., Kim, H.Y., Hong, M., Shin, M. and Bae, H. (2005) Inhibition of Production of Reactive Oxygen Species and Gene Expression Profile by Treatment of Ethanol Extract of Moutan Cortex Radicis in Oxidative Stressed PC12 Cells. Biological and Pharmaceutical Bulletin, 28, 661-666. http://dx.doi.org/10.1248/bpb.28.661

[7] Chen, G., Zhang, L. and Zhu, Y. (2006) Determination of Glycosides and Sugars in Moutan Cortex by Capillary Electrophoresis with Electrochemical Detection. Journal of Pharmaceutical and Biomedical Analysis, 41, 129-134. http://dx.doi.org/10.1016/i.jpba.2005.11.001

[8] Dong, Z.B., Li, S.P., Hong, M. and Zhu, Q. (2005) Hypothesis of Potential Active Components in Angelica Sinensis by Using Biomembrane Extraction and High Performance Liquid Chromatography. Journal of Pharmaceutical and Biomedical Analysis, 38, 664-669. http://dx.doi.org/10.1016/j.jpba.2005.02.008

[9] Ha, D.T., Ngoc, T.M., Lee, I., Lee, Y.M., Kim, J.S., Jung, H., Lee, S., Na, M. and Bae, K. (2009) Inhibitors of Aldose Reductase and Formation of Advanced Glycation End-Products in Moutan Cortex (Paeonia suffruticosa). Journal of Natural Products, 72, 1465-1470. http://dx.doi.org/10.1021/np9002004

[10] Lau, C.H., Chan, C.M., Chan, Y.W., Lau, K.M., Lau, T.W., Lam, F.C., Law, W.T., Che, C.T., Leung, P.C., Fung, K.P., Ho, Y.Y. and Lau, C.B. (2007) Pharmacological Investigations of the Anti-Diabetic Effect of Cortex Moutan and Its Active Component Paeonol. Phytomedicine, 14, 778-784. http://dx.doi.org/10.1016/j.phymed.2007.01.007

[11] Ha, D.T., Trung, T.N., Hien, T.T., Dao, T.T., Yim, N., Ngoc, T.M., Oh, W.K. and Bae, K. (2010) Selected Compounds Derived from Moutan Cortex Stimulated Glucose Uptake and Glycogen Synthesis via AMPK Activation in Human HepG2 Cells. Journal of Ethnopharmacology, 131, 417-424. http://dx.doi.org/10.1016/j.jep.2010.07.010

[12] Koo, Y.K., Kim, J.M., Koo, J.Y., Kang, S.S., Bae, K., Kim, Y.S., Chung, J.H. and Yun-Choi, H.S. (2010) Platelet Anti-Aggregatory and Blood Anti-Coagulant Effects of Compounds Isolated from Paeonia lactiflora and Paeonia suffruticosa. Pharmazie, 65, 624-628.

[13] Zhang, M.H., Feng, L., Zhu, M.M., Gu, J.F., Wu, C. and Jia, X.B. (2013) Antioxidative and Anti-Inflammatory Activities of Paeoniflorin and Oxypaeoniflora on AGEs-Induced Mesangial Cell Damage. Planta Medica, 79, 1319 1323. http://dx.doi.org/10.1055/s-0033-1350649

[14] Huang, X., Kong, L., Li, X., Chen, X., Guo, M. and Zou, H. (2004) Strategy for Analysis and Screening of Bioactive Compounds in Traditional Chinese Medicines. Journal of Chromatography B, 812, 71-84. http://dx.doi.org/10.1016/j.jchromb.2004.06.046

[15] Liu, Y., Liu, J., Yin, P., Gao, M., Deng, C. and Zhang, X. (2011) High Throughput Identification of Components from Traditional Chinese Medicine Herbs by Utilizing Graphene or Graphene Oxide as MALDI-TOF-MS Matrix. Journal of Mass Spectrometry, 46, 804-815. http://dx.doi.org/10.1002/jms.1952

[16] Wang, Y., Fan, X., Qu, H., Gao, X. and Cheng, Y. (2012) Strategies and Techniques for Multi-Component Drug Design from Medicinal Herbs and Traditional Chinese Medicine. Current Topics in Medicinal Chemistry, 12, $1356-1362$. 
http://dx.doi.org/10.2174/156802612801319034

[17] Yu, L., Zhao, J., Zhu, Q. and Li, S.P. (2007) Macrophage Biospecific Extraction and High Performance Liquid Chromatography for Hypothesis of Immunological Active Components in Cordyceps sinensis. Journal of Pharmaceutical and Biomedical Analysis, 44, 439-443. http://dx.doi.org/10.1016/j.jpba.2007.01.003

[18] Li, Y., Liu, S., Zhang, Z., Xu, Q., Xie, F., Wang, J., Ping, S., Li, C., Wang, Z., Zhang, M., Huang, J., Chen, D., Hu, L. and Li, C. (2012) RAGE Mediates Accelerated Diabetic Vein Graft Atherosclerosis Induced by Combined Mechanical Stress and AGEs via Synergistic ERK Activation. PLoS ONE, 7, e35016. http://dx.doi.org/10.1371/journal.pone.0035016

[19] Kim, J.Y., Park, H.K., Yoon, J.S., Kim, S.J., Kim, E.S., Ahn, K.S., Kim, D.S., Yoon, S.S., Kim, B.K. and Lee, Y.Y. (2008) Advanced Glycation End Product (AGE)-Induced Proliferation of HEL Cells via Receptor for AGE-Related Signal Pathways. International Journal of Oncology, 33, 493-501.

[20] Zhang, M.H., Feng, L., Zhu, M.M., Gu, J.F., Jiang, J., Cheng, X.D., Ding, S.M., Wu, C. and Jia, X.B. (2014) The Anti-Inflammation Effect of Moutan Cortex on Advanced Glycation End Products-Induced Rat Mesangial Cells Dysfunction and High-Glucose-Fat Diet and Streptozotocin-Induced Diabetic Nephropathy Rats. Journal of Ethnopharmacology, 151, 591-600. http://dx.doi.org/10.1016/j.jep.2013.11.015

[21] Yu, L., Li, Y., Fan, H., Duan, J., Zhu, Q. and Li, S. (2011) Analysis of Marker Compounds with Anti-Platelet Aggregation Effects in Mailuoning Injection Using Platelet Binding Assay Combined with HPLC-DAD-ESI-MS and Solid-Phase Extraction Technique. Phytochemical Analysis, 22, 87-93. http://dx.doi.org/10.1002/pca.1260

[22] Schnaper, H.W., Hayashida, T., Hubchak, S.C. and Poncelet, A.C. (2003) TGF-Beta Signal Transduction and Mesangial Cell Fibrogenesis. American Journal of Physiology—Renal Physiology, 284, F243-F252. http://dx.doi.org/10.1152/ajprenal.00300.2002

[23] Fukami, K., Yamagishi, S., Ueda, S. and Okuda, S. (2008) Role of AGEs in Diabetic Nephropathy. Current Pharmaceutical Design, 14, 946-952. http://dx.doi.org/10.2174/138161208784139710

[24] Yamagishi, S., Nakamura, K. and Matsui, T. (2009) Regulation of Advanced Glycation End Product (AGE)-Receptor (RAGE) System by PPAR-Gamma Agonists and Its Implication in Cardiovascular Disease. Pharmacological Research, 60, 174-178. http://dx.doi.org/10.1016/j.phrs.2009.01.006

[25] Xu, S.J., Yang, L., Zeng, X., Zhang, M. and Wang, Z.T. (2006) Characterization of Compounds in the Chinese Herbal Drug Mu-Dan-Pi by Liquid Chromatography Coupled to Electrospray Ionization Mass Spectrometry. Rapid Communications in Mass Spectrometry, 20, 3275-3288. http://dx.doi.org/10.1002/rcm.2717

[26] Lin, H.C., Ding, H.Y. and Wu, Y.C. (1998) Two Novel Compounds from Paeonia suffructicosa. Journal of Natural Products, 61, 343-346. http://dx.doi.org/10.1021/np9704258

[27] Wu, J., Shen, H., Xu, J., Zhu, L.Y., Jia, X.B. and Li, S. (2012) Detection of Sulfur-Fumigated Paeoniae Alba Radix in Complex Preparations by High Performance Liquid Chromatography Tandem Mass Spectrometry. Molecules, 17, 8938-8954. http://dx.doi.org/10.3390/molecules17088938

[28] Liu, J.P., Wang, S., Feng, L., Ma, D., Fu, Q., Song, Y., Jia, X.B. and Ma, S. (2013) Hypoglycemic and Antioxidant Activities of Paeonol and Its Beneficial Effect on Diabetic Encephalopathy in Streptozotocin-Induced Diabetic Rats. Journal of Medicinal Food, 16, 577-586. http://dx.doi.org/10.1089/jmf.2012.2654

\section{Abbreviations}

AGEs: advanced glycation end products; BSA: bovine serum albumin; CMC: cell membrane immobilized chromatography; DMEM: Dulbecco's modified Eagle's medium; DN: diabetic nephropathy; FBS: fetal bovine serum; MC: Moutan Cortex; TCMs: traditional Chinese medicines. 